\title{
METHODS OF STANDARDIZING ACID SOLUTIONS.
}

BY CYRIL G. HOPKINS.

Received July 23, sgor.

THE recent articles on "The Preparation of an Exact Standard Acid" and "The Electrolysis of Copper Sulphate as a Basis for Acidimetry," by Higgins ${ }^{1}$ and Kohn, ${ }^{2}$ respectively, both of whom appear to have overlooked the fact that this electrolytic method for standardizing acids was introduced by Hart and Croasdale ${ }^{3}$ more than ten years ago, have suggested that a series of results obtained by the writer, in a comparative study ${ }^{*}$ of "Methods of Standardizing Reagents Used in Acidimetry and Alkalimetry," would add something of interest and value on the subject, especially to such as are interested in volumetric analysis.

The special object in this study was to determine the most exact method of standardizing a solution of acid for subsequent use as "standard acid," this being the ultimate and practical purpose of any basis for acidimetry.

Six different methods of standardizing acid solutions were investigated and compared:

I. The silver chloride method of standardizing hydrochloric acid with some modifications and improvements as to manipulation.

2. The method of standardizing sulphuric acid by weighing as ammonium sulphate, as recommended by Wenig. ${ }^{\circ}$

3. The method of using metallic sodium, introduced by Hartley and improved by Neitzel.

4. The method of standardizing acids by use of pure crystallized borax.

5. The method based upon the electrolysis of copper sulphate, introduced by Hart and Croasdale ${ }^{8}$ and strongly recommended by Hart $^{9}$ and recently rediscovered by Kohn. ${ }^{10}$

'J. Soc. Chem. Ind., 19, 958 (1900).

2 Ibid., 19, 962 (1900).

3 J. Anal. Chem., 4, 424 (1890).

4 Author's unpublished thesis for the degree of Master of Science, Cornell University, 1894. Acknowledgment is made of valuable suggestions from Dr. G. C. Caldwell, under whose supervision this work was done.

s Zischr.angew. Chem., (1892), 204.

- Quar. Jour. Chem. Soc., 26, $123(1873)$.

i Ztschr. anal, Chem., 32, 422 (1893).

$8 \mathrm{~J}$. Anal. Chem., 4, 424 (1890).

- Ibit., 6, 421 (1892).

$10 \mathrm{~J}$. Soc. Chem. Ind., 19, g62 (1900). 
6. The method of standardizing oxalic acid by means of metallic iron and potassium permanganate.

Before the details of the results obtained in this work are considered, it is desired to call attention to two questions which have important effects upon accuracy in different methods of standardizing :

I. Is the method of standardizing direct or indirect ?

2. Is the actual error which may be made in the determination of the substance which is brought to the balance mathematically increased or diminished by computing to the equivalent amount of the acid standardized?

In consilering the first question a classification may be made of (1) direct, (2) indirect, and (3) doubly indirect methods, the direct methods requiring only a gravimetric determination, the indirect requiring a gravimetric and a volumetric determination, or a weighing and a titration, and the doubly indirect methods requiring one weighing and two titrations.

The silver chloride and ammonium sulphate methods are direct, the chlorine being precipitated and weighed as silver chloride, and the sulphuric acid being neutralized and weighed as ammonium sulphate.

The metallic sodium and borax methods are indirect, the sodium and the borax each being weighed and then, after being put in solution, titrated to standardize the acid.

The copper sulphate and iron-permanganate methods are doubly indirect, each requiring one weighing and two titrations. The copper is deposited and weighed, the small amount of sulphuric acid liberated titrated against an alkaline solution, and this in turn titrated to standardize the permanent acid solution. The iron is likewise weighed, then put into solution, titrated against permanganate solution, and this solution titrated against the oxalic acid.

To answer the second question we must compare the weight of the substance which is brought to the balance with the weight of the equivalent (but not equal) amonnt of the standard acid. In all of the methods, one of the numbers from which the strength of the standard acid is calculated is obtained by using the balance. The substance weighed is our real hasis for computation. In the two direct methods it is silver chloride and ammonimm sulphate; in the indireet nethods it is sodim and borax, and in the cionbly 
indirect methods it is copper and iron. The accuracy of the manipulation and the purity of the substance are important factors in obtaining correct weights of these substances, and the ratio which a given quantity of the weighed substance bears to the equivalent amount of the acid standardized is an important consideration. Following is a tabular statement arranged to show a comparison of these ratios in the six methods, the numbers being determined by the reactions in each case and reduced to the basis of monobasic acid :

$\begin{gathered}\text { Substances } \\ \text { weighed. }\end{gathered}$
I $43.39 \mathrm{AgCl}$
$66.10\left(\mathrm{NH}_{4}\right)_{2} \mathrm{SO}_{4}$
$23.06 \mathrm{Na}$
$191.15 \mathrm{Na}_{2} \mathrm{~B}_{4} \mathrm{O}_{7} . \mathrm{IOH}_{2} \mathrm{O}$
$31.80 \mathrm{Cu}$
$56.00 \mathrm{Fe}$

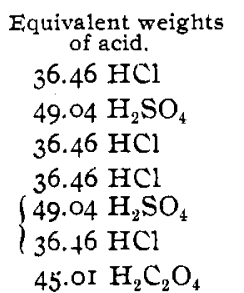

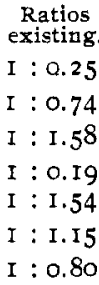

From this table it can be seen that an error of I mg. in the purity or in the manipulation in securing the weight of the sodium would cause an error of $1.58 \mathrm{mg}$. in the equivalent amount of standard hydrochloric acid; while the same error, I mg., in obtaining the weight of borax would cause an error of only 0.19 $\mathrm{mg}$. in the equivalent amount of standard acid. In other words, an error of I $\mathrm{mg}$. in obtaining the weight of sodium would have the same influence on the accuracy of the determination of the strength of the standard acid as would an error of $8.3 \mathrm{mg}$. in obtaining the weight of borax, equivalent amounts of each (sufficient to neutralize the same quantity of acid) being taken. Similarly, I mg. error in obtaining the weight of copper would have the same influence on standard sulphuric acid as would an error of $6.2 \mathrm{mg}$. in the weight of silver chloride on standard hydrochloric acid. These are certainly considerations which should be taken into account, as they may very materially affect the possible accuracy of methods.

Following are statements of results obtained by each method with as brief descriptions as seem practicable of processes of manipulation :

I. Silver Chloride Method.-Standardizing hydrochloric acid by precipitating with silver nitrate and weighing the silver chloride. 
A solution of hydrochloric acid of about one-fourth normal strength was prepared for standardizing. Portions of the acid solution were measured out with a pipette, the exact capacity of which was found by calibration with mercury to be $50.06 \mathrm{cc}$. The solution was delivered into a $250 \mathrm{cc}$. Erlenmeyer flask provided with a clean, smooth, close-fitting, solid rubber stopper, the pipette being rinsed with a few cubic centimeters of pure water (which was added to the measured acid), and then dried before again being used. All measurements were reduced ${ }^{1}$ to a uniform temperature of $20^{\circ} \mathrm{C}$.

A sufficient quantity (as determined by stoichiometric computation) of a 5 per cent. solution of silver nitrate to nearly, but not quite completely, precipitate all of the chlorine, was at once added, the necessary additional quantity being added in less than I cc. portions. The flask was closed with a rubber stopper ${ }^{2}$ and shaken after each addition, so that the precipitate would settle and it could easily be known when sufficient precipitant had been added, a large excess of silver nitrate, which would possess some solvent action on the silver chloride and necessitate much washing for its complete removal from the precipitate, thus being avoided.

After the precipitation was complete, the flask was shaken until, after standing a short time, the supernatant liquid became perfectly clear. It was then allowed to stand in an inclined position until the precipitate settled down quite compactly in the bend of the flask. The solution was then poured off through a Gooch crucible as completely as possible without transferring more than a mere trace of the precipitate. The flask was then set aside in an inclined position, such that the precipitate was not at the lowest point, where the remaining liquid would collect. After two or three minutes the liquid, which had drained out of the precipitate, was also poured through the filter. About roo cc. of pure water containing a trace of nitric acid, ${ }^{3}$ sufficient only to make it distinctly acid, were now poured into the flask, which was then closed and thoroughly shaken, the precipitate allowed to settle, and the liquid twice decanted just as before. This

1 Schulze: "Expansion of Iriquids in Glass Vessels," Ztschr. anal. Chem., 21, 167 (1852). flask.

2 Whenever the stopper is removed it must, of course, be carefully rinsed of into the

3 In perfectly pure water, silver chloride does not cohere well, but remains persistently in very fine particles; indeed, after it has been well collected in large particles by being shaken in an acid solution, it will separate again into fine particles if shaken with pure water. 
treatment was repeated with another $100 \mathrm{cc}$. of the wash-water, after which the precipitate was again shaken with the washwater and then transferred to the crucible. The last traces are quickly and easily and completely transferred, simply by the use of a good "spritz" bottle, the flask being inclined mouth downward over the crucible and rotated during the operation. The "transfer" wash-water gave no test for silver. ${ }^{1}$ The precipitate was heated in the air-bath at $130^{\circ}$ to $150^{\circ}$ to constant weight.

Six determinations gave the following results:

$\begin{array}{cccccc}\begin{array}{c}\text { Solution } \\ \text { taken. } \\ \text { cc. }\end{array} & \begin{array}{c}\text { Temper- } \\ \text { ature. }\end{array} & \begin{array}{c}\text { AgCl } \\ \text { found. } \\ \text { Gram. }\end{array} & \begin{array}{c}\text { AgCl from } 50.06 \mathrm{cc} . \\ \text { at } 20^{\circ} . \\ \text { Gram. }\end{array} & \begin{array}{c}\mathrm{HCl} \mathrm{in} \mathrm{I} \mathrm{ce} \\ \text { at 20 } \\ \text { mg. }\end{array} \\ 1 & 50.06 & 20.0^{\circ} & 1.9310 & 1.9310 & 9.808 \\ 2 & 50.06 & 20.0^{\circ} & 1.9312 & 1.9312 & 9.809 \\ 3 & 50.06 & 23.5^{\circ} & 1.9295 & 1.9310 & 9.808 \\ 4 & 50.06 & 23.5^{\circ} & 1.9292 & 1.9307 & 9.807 \\ 5 & 50.06 & 22.0^{\circ} & 1.9301 & 1.9309 & 9.808 \\ 6 & 50.06 & 22.0^{\circ} & \text { I.930I } & \text { I.9309 } & 9.808\end{array}$

Another solution of hydrochloric acid of slightly greater strength was subsequently standardized by using the method just described, and in doing this work an attempt was made to determine the exact loss of silver chloride (if there be any loss) incurred by this method of washing. In the following determinations, Nos. I, 2, 3, and 4 were washed exactly as described above, while Nos. 5 and 6 were washed just five times as much by exactly the same method of washing. Regularly three portions of roo cc. each of liquid are decanted from the precipitate, and the precipitate is then transferred with a roo cc. portion of wash liquid; but in Nos. 5 and 6 (below) this fourth roo cc. portion was also decanted each time until the last of the five complete washings, when, of course, it was used in transferring the precipitate. Furthermore, in order that the solvent action of the five complete washings should produce an effect equal to five times the effect of the one necessary washing, an addition of I cc. of the silver nitrate solution was made to the first roo cc. of washwater used in each of the four extra washings.

\footnotetext{
1 When working with duplicates this method of washing by thotough decantation takes little extra time, and not more than 1 or $2 \mathrm{cc}$. of liquid will be left in the precipitate. The excess of silver uitrate solution added in the precipitation contains only about $50 \mathrm{mg}$. of silver nitrate, and the volume of liquid, when the precipitation is complete, is at least $100 \mathrm{cc}$. Suppose that $5 \mathrm{cc}$. of this remains with the precipitate after shaking and decanting; by theory this should retain only $2.5 \mathrm{mg}$. of silver nitrate. After the second I00 cc. is decanted, about $0.1 \mathrm{mg}$. of silver nitrate would be left in the flask. and, after the third decantation, only $0.005 \mathrm{mg}$., an unweighable quantity, of silver nitrate would remain with the silver chloride precipitate. The fact that not a trace of silver was found in the washwater after the transfer of the precipitate proves this theory correct in practice.
} 
Six determinations gave the following results :

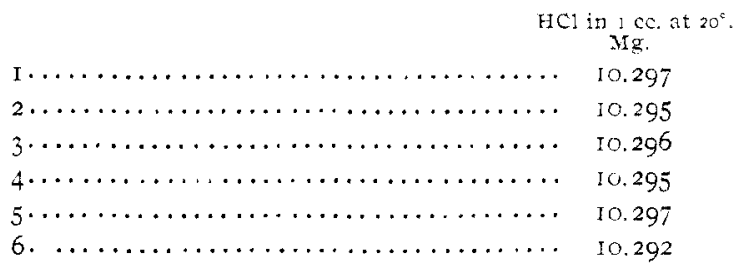

The results show that there is certainly no appreciable loss of silver chloride by this process of washing.

These twelve results (in two sets) include all of the determinations which were made by the method just described; in other words, all results obtained are here reported. These results and seven years of subsequent experience ${ }^{2}$ with the method lead me to confidently assert that by this method a skilled manipulator can easily and quickly make determinations of hydrochloric acid within a limit of error of $0.5 \mathrm{mg}$. of silver chloride on 2 grams of precipitate.

2. Ammonium Sulphate Method.-Standardizing sulphuric acid by neutralizing the acid solution with ammonium hydroxide, evaporating to dryness, and weighing the ammonium sulphate. This was first recommended in I 892 by M. Wenig."

A solution of about one-fourth normal sulphuric acid was used. Portions of $50.06 \mathrm{cc}$. were measured out and delivered into a weighed platinum dish. Ammonium hydroxide was then added in slight excess, the solution evaporated to dryness on the waterbath, and the residue dried to constant weight at $120^{\circ}$.

The ammonium hydroxide was distilled just before using. The sulphuric acid was free from nitrogen and the residue of ammonium sulphate was completely volatile upon gentle ignition, showing the absence of fixed bases.

Six determinations of the sulphuric acid in the standard solu-

1 These figures are taken from a copy of the thesis already referred to. The laboratory note-book in which the full record of the determinations was preserved has been subsequently lost in a fire, hence the complete data, including weights of silver chloride, etc., cannot be given.

"The following are duplicate determinations on four different solutions of hydrochloric acid which have been standardized in the course of ordinary work (weights of silver chloride are given) :

\begin{tabular}{|c|c|c|c|c|}
\hline 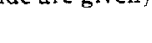 & I. & Gram. & Grams. & Grains. \\
\hline $\mathrm{ACl}$ found & 1.4103 & 1.4062 & 3.2173 & 1.2296 \\
\hline AgCl tound & 1.4104 & 1.4064 & 1.2177 & I. 2295 \\
\hline
\end{tabular}


tion were made by this method, with the following results (in No. 2 a slight mechanical loss of ammonium sulphate occurred):

$\begin{array}{cccccc}\begin{array}{c}\text { Solution } \\ \text { taken. } \\ \text { cc. }\end{array} & \text { Temperature. } & \begin{array}{c}\left(\mathrm{NH}_{4}\right)_{2} \mathrm{SO}_{4} \\ \text { found. } \\ \text { Gram. }\end{array} & \begin{array}{c}\left(\mathrm{NH}_{4}\right)_{2} \mathrm{SO}_{4} \text { from } \\ 50.06 \mathrm{cc}_{4} \text { at } 20^{\circ} . \\ \mathrm{Gram} .\end{array} & \begin{array}{c}\mathrm{H}_{2} \mathrm{SO}_{4} \text { in 1 } \\ \text { at } 20^{\circ} \text { cc. } \\ \text { mg. }\end{array} \\ \mathrm{I} & 50.06 & 19.5^{\circ} & 0.7808 & 0.7807 & 11.570 \\ 2 & 50.06 & 19.5^{\circ} & 0.7795(?) & 0.7794(?) & 11.549(?) \\ 3 & 50.06 & 20.5^{\circ} & 0.7806 & 0.7807 & 11.570 \\ 4 & 50.06 & 20.5^{\circ} & 0.7809 & 0.7810 & 11.574 \\ 5 & 50.06 & 19.0^{\circ} & 0.7809 & 0.7807 & 11.570 \\ 6 & 50.06 & 19.0^{\circ} & 0.7808 & 0.7806 & 11.569\end{array}$

No. 2 being omitted, these weights of ammonium sulphate from $50.06 \mathrm{cc}$. of solution, at $20^{\circ}$, agree within $0.4 \mathrm{mg}$. on nearly 0.8 gram of residue and they indicate that this method of standardizing sulphuric acid is exceedingly accurate. The method is certainly simple and rapid. A comparison of the results obtained by this and the other methods is given below.

3. Sodium Method.-Standardizing acids by the use of metallic sodium.

The use of metallic sodium as a basis for acidimetry was first recommended in 1873 by Hartley. ${ }^{1}$ In I 893 Neitzel $^{2}$ suggested that the sodium be weighed under petroleum in a small beaker instead of in weighing-tubes as recommended by Hartley.

I found a small glass-stoppered weighing-bottle to be an improvement over the beaker, as the petroleum is appreciably volatile at the ordinary temperature. The petroleum was distilled over sodium before being used, that portion being taken which distilled above $200^{\circ}$.

The sodium was cut out as rapidly as possible from a block of the metal, a piece with clean metallic surfaces being thus obtained. With a pair of forceps, it was quickly placed into a weighing-bottle containing sufficient petroleum to cover it. After being weighed, the sodium was dissolved in neutral alcohol in an Erlenmeyer flask which was connected with a reflux condenser. The solution was diluted with water (poured in through the condenser tube) and then titrated against standard acid.

Phenolphthalein was used as an indicator, giving a very sharp and satisfactory " end-reaction."

The burette used was carefully calibrated and the burette readings were taken to hundredths of a cubic centimeter as accurately as possible.

${ }^{1}$ Quar: J. Chem. Soc., 26, 123 (1873).

2 Zischr. anal. Chem., 32, 422 (1893). 
Six determinations gave the following results :

\begin{tabular}{|c|c|c|c|c|c|c|}
\hline & $\begin{array}{l}\text { Metallic } \\
\text { sodiums } \\
\text { taken. } \\
\text { Gram. }\end{array}$ & $\begin{array}{l}\text { Acid }(\mathrm{HCl}) \\
\text { solution } \\
\text { required. } \\
\text { cc. }\end{array}$ & $\begin{array}{l}\text { Tempera. } \\
\text { ture. }\end{array}$ & $\begin{array}{l}\text { Acid solu- } \\
\text { tion required } \\
\text { at } 20^{\circ} \\
\text { cc. }\end{array}$ & $\begin{array}{l}\text { Acid solution at } \\
10^{\circ} \text { required for } \\
0.7154 \text { gram } \\
\text { sodium. } \\
\text { cc. }\end{array}$ & $\begin{array}{l}\mathrm{HCl} \text { in } \\
\pm \mathrm{Cc} . \\
\text { at } 20^{\circ} \text {. } \\
\text { mg. }\end{array}$ \\
\hline & 0.8853 & 142.10 & $23.5^{\circ}$ & $r 42.00$ & I 14.75 & 9.857 \\
\hline & $0.635^{8}$ & I01.95 & $23.5^{\circ}$ & IоI 88 & I I 4.63 & 9.867 \\
\hline & $0.935^{2}$ & I 50.45 & $27.0^{\circ}$ & I50.2 I & I 14.91 & 9.843 \\
\hline & 0.7004 & $\mathrm{II} 2.40$ & $26.0^{\circ}$ & I 12.25 & I 4.65 & 9.865 \\
\hline & 0.6229 & 100.00 & $22.0^{\circ}$ & 99.96 & II 4.80 & 9.853 \\
\hline & $0.5[28$ & 82.47 & $23.0^{\circ}$ & 82.42 & I 4.98 & 9.837 \\
\hline
\end{tabular}

As standardized by the silver method (average of six determinations) this acid contained in I cc. $9.808 \mathrm{mg}$. hydrochloric acid. The following two determinations (only) were made to standardize the sulphuric acid solution by use of metallic sodium. The results follow :

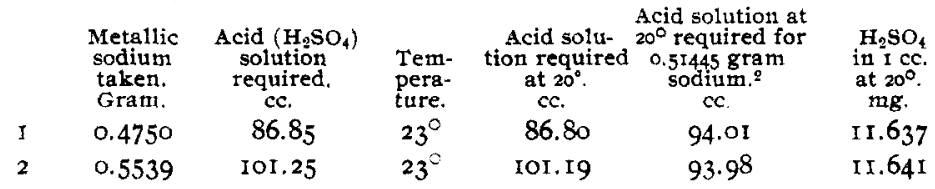

As standardized by the ammonium sulphate method (average of the five trustworthy determinations) this acid contained in I cc. II.57 I mg. sulphuric acid.

It will be observed that the results obtained by the sodium method, with both hydrochloric and sulphuric acids, agree well among themselves, considering that they are obtained by an indirect method which includes volumetric determinations. But it will also be observed that the results obtained by the sodium method are invariably higher than those obtained by the silver chloride and the ammonium sulphate methods. Without doubt this discrepancy is due to impurities contained in the sodium itself. Traces of carbon and iron were easily detected, and the presence of potassium was revealed by the spectroscope. The presence of elements of higher equivalent weights than sodium was indicated by converting the metal to sulphate. Two determinations gave 3.0783 and 3.0781 grams sulphate per gram of metal taken, while by theory I gram sodium is equivalent to 3.0829 grams sodium sulphate. Iron and potassium would each

1 Average amount taken. The number of cubic centimeters given in this colum are computed for each separate determination to show in cubic centimeter: the limit of error in the titrations.

See previous foot-note. 
method was also employed in his work on the atomic weight of boron. ${ }^{1}$

In the following work, C. P. borax was dissolved in water by the aid of heat. As the solution cooled, crystals began to form at about $45^{\circ}$. When the temperature had fallen to $30^{\circ}$, the mother-liquor was drained off, the crystals washed with cold water, placed on drying paper, and dried at the room temperature for four days, being turned occasionally to insure thorough drying. To standardize an acid, the crystallized borax is simply weighed, dissolved in water, and titrated against the acid. The standard hydrochloric acid mentioned as having been standardized by the silver chloride method and found by six closely agreeing determinations to contain $10.295 \mathrm{mg}$. hydrochloric acid in I cc. at $20^{\circ}$, was used in this work.

Ten determinations by means of borax were made, four after four days' exposure to the air, four after five days', and two after six days' exposure, the titrations always being made with the hydrochloric acid solution at $20^{\circ}$. Litmus, as recommended by Salzer, " was used as an indicator in the first four titrations; but the end-reaction was not sharp, and in the subsequent titrations dimethyl orange, as Rimbach recommends, was used. It was very satisfactory.

\begin{tabular}{|c|c|c|c|c|}
\hline & $\begin{array}{c}\mathrm{Na}_{2} \mathrm{~B}_{4} \mathrm{O}_{4}, 10 \mathrm{H}_{2} \mathrm{O} \\
\text { taken. } \\
\text { After four days. } \\
\text { Grams. }\end{array}$ & $\begin{array}{l}\text { Acid required } \\
\text { at } 20^{\circ} . \\
\mathrm{cc} .\end{array}$ & $\begin{array}{c}\text { Acid solution } \\
\text { at } 20^{\circ} \text { required for } \\
5.4944 \mathrm{grams} \\
\text { borax. } \\
\text { cc. }\end{array}$ & $\begin{array}{l}\mathrm{HCl} \text { in } \\
\text { I cc. } \\
\text { at } 20^{\circ} \text {. } \\
\text { mg. }\end{array}$ \\
\hline I & $5 \cdot 3481$ & 99. I & $10 \mathrm{I} .8 \mathrm{I}$ & 10.294 \\
\hline 2 & $5.5 \circ 75$ & IO2. I & 101.86 & 10.289 \\
\hline 3 & 5.3044 & 98.4 & 101.92 & 10.282 \\
\hline \multirow[t]{2}{*}{4} & 5.2895 & $98 . \mathrm{I}$ & IOI.90 & 10.284 \\
\hline & After n̂ve days. & & & \\
\hline 5 & 5.4370 & 101.05 & 102.13 & 10.263 \\
\hline 6 & 5.5977 & 104.05 & 102.13 & 10.262 \\
\hline 7 & 5.4045 & 100.37 & 102.04 & $10.27 \mathrm{I}$ \\
\hline \multirow[t]{2}{*}{8} & 5.4906 & 102.05 & 102.12 & 10.262 \\
\hline & After six days. & & & \\
\hline 9 & $5.289 \mathrm{I}$ & $9^{8.60}$ & 102.43 & 10.231 \\
\hline IO & 6.2754 & II 7.05 & 102.47 & 10.226 \\
\hline
\end{tabular}

Although the results obtained on one and the same day agree well with themselves, especially when dimethyl orange was used as the indicator; yet the results indicate that the borax is not

1 Ber. d. chem. Ges, , 26, 164 (1893).

2 Zischr. anal. Chem., 32, 529 (1893).

3 Average amount taken. 
constant, but that it continually loses water of crystallization. To test this point further, samples of the borax which had been dried by exposure to the air for six days were weighed out and allowed to stand, exposed to the air but protected from the dust.

Following are the weights of the two samples on several subsequent days :

No. of days
drying.
6
7
9
IO

$\begin{array}{lc}\text { I. } & \text { Weight of borax. } \\ \text { Grains. } & \begin{array}{c}2 . \\ \text { Grams. } \\ \text { 9.2214 }\end{array} \\ 9.2132 & 10.0762 \\ 9.1920 & 10.0646 \\ 9.1738 & 10.0396 \\ \text { 9. } & 10.0135\end{array}$

It is evident that the borax continually lost water of crystallization whether exposed to the air on drying paper or kept in open vessels. Rimbach found that crystallized borax remained constant after three or four days' drying, if kept in the air at the ordinary temperature, but that it lost weight readily when placed in dry air. Of course if the temperature and humidity of the air were such that the vapor-pressure of the atmospheric moisture exceeded that of crystallized borax, then the salt would not effloresce ; and Rimbach may possibly have worked under such conditions.

Copper Sulphate Method.-Standardizing acids by use of the sulphuric acid set free in the electrolysis of copper sulphate. This method was introduced by Hart and Croasdale $^{1}$ in 1890 . It consists in subjecting a solution of pure copper sulphate to electrolysis, weighing the copper deposited, titrating the liberated acid against an alkaline solution, and then using the alkali in standardizing a permanent acid solution. It is thus a doubly indirect method.

In the following work platinum dishes were used for the negative electrodes. The strength of current used corresponded to about $3.5 \mathrm{cc}$. of oxyhydrogen gas per minute. The acid set free was titrated against approximately one-tenth normal solution of sodium hydroxide made from metallic sodium. The alkali was then titrated against standard hydrochloric acid.

The copper sulphate was tested for acidity with methyl orange and found to be perfectly neutral. Tests for other bases than copper gave negative results. After the liberated acid had been

1 I. Anal. Chem., 4, 424 (1890). 
transferred and the platinum dish well rinsed with pure water, the deposited copper was washed with absolute alcohol and the dish dried at the temperature of the hands, excepting in determinations $I$ and 2 , in which the alcohol was drained out well and the last traces burned out as directed by Hart and Croasdale. In determination 2, some of the copper turned bluish green, indicating the formation of a salt of copper combined with some intermediate acid product of combustion. Because of this fact No. 2 is not considered a trustworthy determination.

Because of the large influence on the accuracy of the final results of any error in weighing the copper the weights were all taken by the method of oscillations. ${ }^{1}$ The relation between the standard hydrochloric acid and the sodium hydroxide solutions was determined by titration as follows :

$$
\begin{aligned}
& \text { I } 50.06 \mathrm{cc} \text {. acid required II } 9.37 \mathrm{cc} \text {, alkali. } \\
& 250.06 \text { " " " } " \text { II } \\
& 350.06 \text { " " " } 3 \quad \text { " } 319.4 \text { " " } \\
& \text { Average I " " " " } \quad 2.3^{8} 53 \mathrm{cc} \text {. alkali. }
\end{aligned}
$$

\begin{tabular}{|c|c|c|c|c|}
\hline & $\begin{array}{l}\text { Copper } \\
\text { deposited } \\
\text { from CuSO } \\
\text { Gram. }\end{array}$ & $\begin{array}{l}\text { NaOH solution re- } \\
\text { quired to neutralize } \\
\text { the liberated } \\
\mathrm{H}_{2} \mathrm{SO}_{4} . \\
\text { cc. }\end{array}$ & $\begin{array}{l}\text { HCl solution } \\
\text { equivalent } \\
\text { at } 20^{\circ} \text {. } \\
\text { cc. }\end{array}$ & $\begin{array}{l}\mathrm{HCl} \\
\text { in I cc. } \\
\text { at } 20^{\circ} \\
\text { mg. }\end{array}$ \\
\hline I & o. I 5349 & 42.85 & I 7.964 & 9.796 \\
\hline 2 & 0.16664 (?) & 45.78 & I9. I92 & 9.954 (?) \\
\hline 3 & O. I 5596 & 43.45 & 18.216 & 9.793 \\
\hline 4 & 0.14853 & 41.35 & 17.336 & 9.823 \\
\hline 5 & o. 16719 & $46.5^{8}$ & 19.528 & 9.815 \\
\hline 6 & 0.14921 & 41.57 & 17.428 & 9.816 \\
\hline 7 & 0.16468 & 45.80 & 19.201 & 9.833 \\
\hline 8 & o. 19207 & 53.68 & 22.505 & 9.785 \\
\hline
\end{tabular}

Following are the results of eight determinations of the strength of a standard hydrochloric acid as ascertained by means of the copper sulphate method :

The following table gives a series of results obtained by Hart and Croasdale ${ }^{2}$ in standardizing a solution of sulphuric acid by this method, and, for comparison, the results of my own determinations as just given (except that they are reduced to $0.5 \mathrm{cc}$. acid solution to make the results more comparable, my acid being very much stronger than theirs); and also my results obtained on the same acid solution by the direct silver chloride method, and on a

I Kohlrausch's "Physical Measurements," p. 23, (r\&gl).

2. Anal. Chem, 4, 426 (1890). 
sulphuric acid solution by the ammonium sulphate method (also reduced to $0.5 \mathrm{cc}$.).

$\begin{array}{cc}\begin{array}{c}\text { Hart and Croasdale. } \\ \text { Copper sulphate } \\ \text { method, } \\ \mathrm{H}_{2} \mathrm{SO}_{4} \text { in I cc. } \\ \text { mg. }\end{array} & \begin{array}{c}\text { Hopkins. } \\ \text { Copper sulphate } \\ \text { method, } \\ \text { HCl in i cc. } \\ \text { mg. }\end{array} \\ 4.814 & 4.898 \\ 4.802 & 4.897 \\ 4.791 & 4.912 \\ 4.799 & 4.908 \\ 4.819 & 4.908 \\ 4.8 \mathrm{II} & 4.917 \\ 4.767 & 4.893 \\ \text { Maximum } \\ \text { variation }\end{array}$

\begin{tabular}{|c|c|}
\hline $\begin{array}{c}\text { Hopkins. } \\
\text { Silver chloride } \\
\text { method. } \\
\text { Hcl in } \frac{1}{2} \text { cc. } \\
\text { mg. }\end{array}$ & $\begin{array}{c}\text { Hopkins. } \\
\text { A mmonium sulphate } \\
\text { method, } \\
\mathrm{meth}_{2} \mathrm{SO}_{4} \text { in } 1 \text { cc. } \\
\text { mg. }\end{array}$ \\
\hline 4.904 & 5.785 \\
\hline 4.905 & 5.785 \\
\hline 4.904 & 5.787 \\
\hline 4.904 & 5.785 \\
\hline 4.904 & 5.785 \\
\hline 4.904 & $\cdots$ \\
\hline$\cdots$ & $\cdots$ \\
\hline 0.001 & 0.002 \\
\hline
\end{tabular}

The copper sulphate method of standardizing acids gives fairly satisfactory results, but it falls far short of the direct silver chloride and ammonium sulphate methods in accuracy. The reason for this is found both in the substances used and in the number of manipulations. First, the ratio of the substance weighed to the acid determined is such that an error in obtaining the weight of copper vitiates the final result five or six times as much as an equal error in weighing silver chloride, and twice as.much as an equal error in weighing ammonium sulphate. Further, the amount of copper which can be conveniently deposited in suitable condition for washing and weighing is relatively and absolutely smaller than the amounts of silver chloride or of ammonium sulphate conveniently manipulated. But the still more serious objection to the method is the fact that, even after the weight of copper is obtained, two volumetric determinations are necessary before the strength of the permanent acid solution can be ascertained.

In a second paper" on "Copper Sulphate as a Material for Standardizing Solutions," Dr. Hart appears to have overlooked these objections, as may be seen from the following quotation :

"A committee of the Association of Official Agricultural Chemists have compared our method (Hart and Croasdale's method) with others, and speak well of it. I doubt whether their report adds to the evidence in either direction, however, since their ultimate standard was a solution of hydrochloric acid, the strength of which was determined with silver nitrate. Every chemist 
knows, however, that it is an easy matter to make an error of half a milligram in any method involving a precipitation and the transfer of a precipitate; Croasdale's results and those of Richards show that the error involved is much less when copper is determined by the battery method, and that we can probably determine copper more accurately than any other element, consequently that our method should be taken as the standard and others referred to it."

No question need be raised in regard to the exactness of the electrolytic assay of copper. It is a direct and absolute method for the determination of copper, but the method, based upon that determination, of using the liberated acid for standardizing a permanent acid solution by making two volumetric determinations, and computing from the low equivalent weight of copper (as compared with that of silver chloride) is very indirect and not exceedingly accurate; and this comparative study of methods of standardizing acids has convinced the writer that the objections mentioned to the copper sulphate method are applicable and valid; also that the silver chloride method (as described) and the ammonium sulphate method are extremely accurate and satisfactory for standardizing solutions of hydrochloric and sulphuric acids, respectively.

CNIVERSITY OF ILLINOIS.

[CONTRIBUTIONS FROM THE HAVEMEYER LABORATORIES OF COLUMBIA UNIVERSITY, No. 32.]

\title{
SOME EXPERIMENTS WITH THE MONONITROORTHO- PHTHALIC ACIDS.
}

By Marston Taylor Bogert aNd Leopold Boroschek.

Received August J, 3gor,

\begin{abstract}
A LTHOUGH both mononitro-o-phthalic acids have long been $A$ well known, yet, of their derivatives, with the exception of their salts and esters, only the anhydride, imide, and anil have been described. It seemed, therefore, of interest to prepare some of the other derivaties of these acids and to study their properties, and the present paper records our first experiments along this line.

I The iron-permanganate method gave fairly accurate results as a method for standardizing oxalic acid. It is no more indirect and no less accurate (if the purity of the iron be known) than the copper sulphate method. It is thought that a detailed description here of the work done upon the iron-permangatiate method would not be of special interest of value.
\end{abstract}

